\title{
The Role of Emotional and Cognitive Responses to Sport Video Gaming in Sport Brand Attitude Formation
}

\author{
Yongjae Kim \\ Kutztown University of \\ Pennsylvania, Kutztown, USA
}

\author{
Seungbum Lee \\ University of Akron, \\ Akron, USA
}

\author{
Jina Hyejin Bang \\ Florida International University, \\ Miami, USA
}

\begin{abstract}
The purpose of this study is to develop and test a conceptual model of brand attitude formation using repeated exposure to sport brands in sport video games (SVG); and to examine if the research model has the same pattern across high and low levels of sport brand familiarity. Three hundred seventy five (375) undergraduate students, recruited from two universities in the US, participated in an experiment. Results from structural equation modeling (SEM) provide empirical evidence that the repetition of SVG elicits emotional reactions and cognitive evaluations about sport brands detailed in SVG. This study also confirms that emotional reactions to unfamiliar brands in SVG are indirectly transferred to brand attitudes through SVG attitudes. Indirect effects of brand cognition on brand attitudes through SVG attitudes are evident in high levels of brand familiarity but not in low levels of brand familiarity. The findings lead to managerial implications for marketers and provide researchers with empirical data on how future research can explore the unique participatory experience of sport consumers in a virtual sport environment.
\end{abstract}

Keywords: sport video games (SVG), repeated exposure, sport brands, virtual sport experience

\section{Introduction}

With the growing popularity of sports, sport video games (SVG), emulating real life sports, have been one of the most popular entertainment genres in the United States. The popularity of SVG accounted for $20.6 \%$ of the US video game industry sales ( $\$ 9.25$ billion) in 2011 (Entertainment Software Association, 2012). The Madden NFL (National Football League) series was one of the best-selling games of all time, selling more than 70 million units across all platforms (Broverman, 2010). This entertaining pastime has rapidly grown into a highly-popular activity for all types of sport fans, and this habitual commitment has captured the attention of sport scholars.

Given SVGs are perceived as a component of advertising and promotional strategy to reach a wide range of consumers, there has been a need for sport scholars to understand SVGs as an effective sport marketing channel. However, little empirical research has been conducted to determine the effectiveness of SVG as a marketing tool for specific sport brands. Importantly, several extant studies on SVG have failed to achieve a more realistic exposure environment within the confines of an experimental setting (e.g., Walsh, Kim, \& Ross,

\footnotetext{
Yongjae Kim, Ph.D., associate professor, Department of Sport Management and Leadership Studies, College of Business, Kutztown University of Pennsylvania.

Seungbum Lee, Ph.D., associate professor, School of Sport Science \& Wellness Education, University of Akron.

JinaHyejin Bang, Ph.D., associate professor, Department of Leadership and Professional Studies, Florida International University.
} 
2008). Consequently, little is known about the impact of repeated SVG play. Furthermore, to date no empirical work has been sought to examine how users' emotional and cognitive responses to a sport brand (e.g., sports league) in SVG influence their attitudes toward that particular brand. The lack of research on SVG effectiveness creates a conceptual void in the marketing and communication literature therefore a further examination of SVG is needed to ascertain how users respond to sport brands in SVG and how SVG benefits sport organizations.

Accordingly, the purpose of this study is to propose and test a conceptual framework of sport brand attitude formation as a function of emotions and cognitions generated from repetitive SVG play; and to examine if the research model has the same pattern across different levels of brand familiarity with a sport league. The findings of this study can contribute to the literature by testing the effects of repeated SVG use on sport brand attitudes. Moreover, the results of this study can advance the literature on SVG effectiveness by providing the first empirical evidence regarding the unique participatory experience of sport consumers in a virtual sport environment.

In the current study, a conceptual model is developed based on the implications drawn from three theoretical perspectives in repetition effects, attitudes, and brand familiarity. The theory of repetition effects argues that attitudes are positively affected by exposure frequency (Campbell \& Keller, 2003), thereby predicting a positive relationship between brand attitudes and the level of exposure to brands in SVG. In addition, attitude theory explains that attitudes are formed from emotion and cognition about a stimulus. Finally, repetition effects can be sensitive to the familiarity of the stimulus (Campbell \& Keller, 2003). Adding a brand familiarity construct to our theoretical framework allows us to obtain a more complete picture of SVG effectiveness. The conceptual model (see Figure 1) describes a process in which sport brand attitudes (sports league) are formed on affective and cognitive reaction to a sport brand in SVG with repetition including moderating effects of brand familiarity.

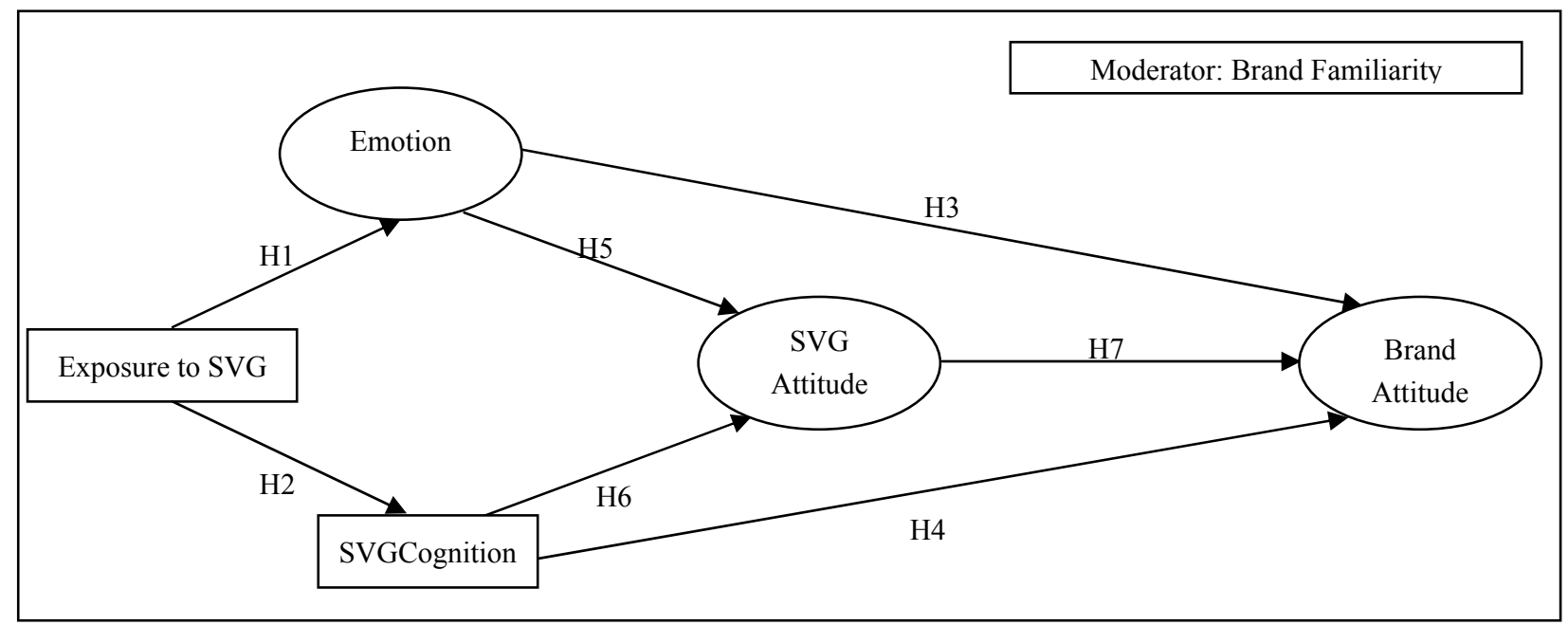

Figure 1. Conceptual model.

\section{Hypotheses Development}

\section{Repetition Effects}

In the field of psychology and marketing, the repetition effect has been studied within attitude 
formation/change paradigms (Cacioppo \& Petty, 1979; Zajonc, 1968). There have been two major perspectives associated with individuals' responses to objects/messages with repetition: affective and cognitive perspectives. From an affective perspective, the leading explanation of repetition effects is based on Zajonc's (1968) mere exposure theory. In a study that examined the attitudinal effects of repeated message exposure, Zajonc (1968) found that mere repeated exposure to a stimulus object produces favorable attitudes toward the object without extensive cognitive operations. Cacioppo and Petty (1979), however, portrayed the repetition effects as results of an elaborate cognitive process. This approach is derived from Fishbein's (1963) attitude model in which the perceived association between a product and its evaluative aspects (e.g., attributes) influences attitudes toward the product. Cacioppo and Petty (1979) provided empirical evidence that advertising repetition stimulates cognitive evaluation about the product in advertising, which in turn influence attitudes toward the product.

Within this paradigm, repeated exposure to sport brands in SVG may enhance sport brand knowledge and positive emotion. Kim (2010) suggested that the interactive and realistic aspects of SVG enable SVG users to interact with sport brands and evaluate information about sport brands. This leads to speculation that SVG repetition may result in increased cognitive elaboration and the strengthened association between a brand representation in memory and its evaluation. In addition, SVG users may feel more positive emotions (e.g., pleasure, excitement, and enjoyment) than negative emotions (e.g., tedium or boredom) when playing SVG repetitively. This is supported by previous studies noting that SVG playing is a form of hedonic consumption behavior for the sake of experience such as fun, enjoyment, and fantasies (Kim \& Ross, 2006; Kwak, Clavio, Eagleman, \& Kim, 2010). Noticeably, the realistic and interactive features of SVG enhance users' enjoyment and consumption level in the SVG context (Kwak et al., 2010). Based on previous literature regarding SVG users' affective and cognitive responses to a sport brand in SVG, the following hypotheses are proposed:

H1: Repeated exposure to a sport brand while playing SVG has a positive effect on affective response (emotion) to the sport brand.

H2: Repeated exposure to a sport brand while playing SVG has a positive effect on cognitive evaluation about the sport brand.

\section{Attitude and Attitude Components}

Attitude can be defined as "a learned predisposition to respond in a consistently favorable manner with respect to a given object" (Fishbein \& Ajzen, 1972, p. 6). It is assumed that attitude reflects a person's feelings toward an object and can be measured on an evaluative continuum ranging from positive to negative or favorable to unfavorable (Cacioppo \& Petty, 1981; Fishbein \& Ajzen, 1972). Attitude scholars have begun to view attitude as a construct comprised of both cognitive and affective components (Katz \& Stotland, 1959; Rosenberg, 1968). In the two component views, attitude formation can be seen as the result of perception and judgment of the consumption experience (cognition) and emotions or feelings about the object (affect).

This provides insight into the effects of cognitive and affective reaction to sport brands in SVG on attitude formation. SVG is a form of entertainment because SVG users are seeking its hedonic value through SVG (Kim \& Ross, 2006). The repetitive use of SVG leads to the users' skill development and mastery at an appropriate pace as they progress through SVG, and subsequently enhanced game experiences (Kwak et al., 2010). Positive emotions generated from SVG may transfer to positive brand attitudes. In other words, pleasurable gaming experiences may lead to positive attitudes toward the sport brand, and reinforce the actual sport brand's image. Based on previous research findings, the following hypotheses are proposed: 
H3: Affective response (emotion of pleasure) elicited by SVG has a positive effect on attitudes toward sport brand embedded in SVG.

H4: Cognitive evaluation about the sport brand has a positive effect on attitudes toward the sport brand embedded in SVG.

\section{Attitudes Toward SVG and Sport Brand}

Advertising researchers have demonstrated the effect of attitudes toward the ad on advertising effectiveness (Erdley \& D’Agostino, 1988; MacKenzie \& Lutz, 1989). Edell and Burke (1987) developed the attitude-toward-the ad model in which feelings (affects) and judgments (cognitions) acquired from exposure to advertising are transferred to attitudes toward advertising, and subsequently to brand attitudes. In the model, feelings elicited by advertising and the informative value of advertising create consumer's beliefs about the ad, which influences overall perceptions of advertising. Specific to ads in video and computer games, Nelson, Keum, and Yaros (2004) argued that game users are more likely to show positive attitudes toward advergame, a game created to promote a brand and its product, when they view the games as a useful source of information or entertainment.

The attitude-toward-the ad model provides insight into the effect of emotions and cognitions generated from SVG on attitudes toward SVG. Positive emotions generated from SVG as a form of entertainment may transfer to positive attitudes toward the SVG. In addition, consumer's underlying beliefs associated with the informative value of SVG may result in favorable attitudes toward SVG. Based on previous literature regarding SVG users' emotion and cognition in SVG as key determinants of SVG attitudes, the following hypotheses are proposed:

H5: Emotion of pleasure elicited by SVG playing has a positive effect on attitudes toward SVG.

H6: Cognitive evaluation about a sport brand in SVG has a positive effect on attitudes toward SVG.

Previous research has shown that attitudes toward advertising are the most noteworthy indicator of advertising effectiveness and outcomes (Aaker \& Stayman, 1990; Harley \& Baldinger, 1991; MacKenzie, Lutz, \& Belch, 1986). For example, Harley and Baldinger (1991) found that the degree to which audiences like an advertisement is the foremost predictor of sales. Similarly, MacKenzie et al.'s (1986) independent influence model explicates a direct impact of attitudes toward advertisement on brand attitudes.

Considering that SVG users are sport consumers (Kim et al., 2008), it is speculated that sport experiences in real life influence attitudes toward SVG, and pleasure generated from video gaming may be transferred to positive attitudes toward the actual sport. Therefore, the following hypothesis was developed to examine the relationship between attitudes toward SVG and sport brand:

H7: Attitudes toward SVG has a positive effect on attitudes toward the sport brand in SVG.

\section{Role of Brand Familiarity in Brand Attitude Formation}

In the communication and marketing literature, many studies show that repetition effects can be sensitive to the familiarity of attitudinal objects (e.g., Cacioppo \& Petty, 1979; Calder \& Sternthal, 1980). Familiar and unfamiliar brands differ in terms of a consumer's knowledge and experience with a brand (Kent \& Allen, 1994). When repetitively exposed to familiar brands in advertising, consumers tend to rely on prior brand knowledge and experience in forming attitudes toward the brand and, therefore are more likely to engage in relatively less involved processing. Whereas consumers, when exposed to messages for unfamiliar brands, are more likely to elicit highly involved, more extensive processing. Specifically, they tend to draw on attitudes toward the 
advertising in forming attitudes toward an unfamiliar brand due to the lack of prior knowledge and experience. On the contrary, when consumers are exposed to messages for unfamiliar brands, the messages appear more interesting to them because of an opportunity to learn about and form an impression of the brand. Noticeably, initial uncertainty or negativity to unfamiliar brands decrease with repetition, and subsequently may lead to positive reaction to the brands (Cacioppo \& Petty, 1979; Campbell \& Keller, 2003; Vakratsas \& Ambler, 1999).

Therefore, it is anticipated that brand familiarity influences SVG repetition effectiveness, moderating the relationship between repetition and consumers' response to messages. Based on the literature review on the moderating effects of brand familiarity, the following hypothesis was proposed:

H8: Levels of brand familiarity will moderate a process by which repeated SVG playing influences attitudes toward a sport brand in SVG.

\section{Methods}

\section{Procedure and Participants}

The research was conducted at a large Midwest university and a medium-size east coast university in the United States. Using a convenience sampling technique, subjects were recruited through classroom announcements asking for volunteers for a 30-50 minute-long study. The research sample consisted of 375 undergraduate students studying in different fields (e.g., advertising, business, kinesiology, science, and law). Each subject was randomly assigned to one of three experimental conditions: one, three, or five exposures. In the single-exposure treatment group, subjects were asked to play a 10 minute segment of SVG after a trial session (5 minutes). Similarly, subjects in the three and five exposure conditions were asked to play two or four additional times respectively. It is important to note that subjects all played with the same game setting (e.g., team, players, league, weather, and stadium). After playing SVG, subjects were instructed to complete a given questionnaire. The information from the completed surveys was analyzed with AMOS 18 and SPSS 18.0. For the purpose of the study, a soccer-themed-video game was selected as test material because the SVG emulating a game of soccer is very realistic and interactive and is easy to learn and play. Also this game allows the users to select a league (sport brand) to play.

\section{Measurements}

Exposure to SVG. Level of SVG exposure was determined based on each experimental condition. For instance, individuals in the single exposure group were assigned one as the level of exposure to SVG.

Emotion. To measure emotion elicited by repeated SVG play, the study used positive emotional items identified by Edell and Burke (1987). The emotion measure consisted of three items ("Excited," "Joyful," and "Pleased") with a 7-point semantic differential scale with ranging from "Not at all" (1) to "Extremely" (7). Biscaia, Correia, Rosado, Maroco, and Ross (2012) have established its validity and reliability.

Cognitive evaluation about the sport brand. In this study, a standard thought-listing procedure was employed as a method of cognitive assessment (Cacioppo \& Petty, 1981). Subjects were asked to list their thoughts about the sport brand for five minutes after playing SVG. Once collected, the semantic contents of cognitive responses (i.e., listed thoughts) were coded into the sport brand related thought categories by two judges who were blind to the experiment and the research hypotheses. The authors and judges agreed on the category for $95 \%$ of individuals' thoughts related to the sport brand. The responses in which judges did not 
reach agreement were not used in the current study. Cognitive response values were calculated by subtracting the number of negative statements from the corresponding total number of positive statements. Means and standard deviations of these cognitive response indices are reported in Table 1.

Table 1

Factor Loadings, Critical Ratios, Composite Reliability (CR), Average Variance Extracted (AVE), Mean (M), and Standard Deviation (SD)

\begin{tabular}{|c|c|c|c|c|c|c|c|}
\hline \multirow{2}{*}{ Factor } & \multirow{2}{*}{ Item } & \multicolumn{2}{|c|}{ Total } & \multicolumn{2}{|c|}{$\begin{array}{l}\text { High Brand Familiarity } \\
\text { Group }\end{array}$} & \multicolumn{2}{|c|}{$\begin{array}{l}\text { Low Brand Familiarity } \\
\text { Group }\end{array}$} \\
\hline & & $\lambda_{X}$ & $\begin{array}{l}\text { Critical } \\
\text { Ratio }\end{array}$ & $\lambda_{X}$ & $\begin{array}{l}\text { Critical } \\
\text { Ratio }\end{array}$ & $\lambda_{X}$ & $\begin{array}{l}\text { Critical } \\
\text { Ratio }\end{array}$ \\
\hline Exposure to SVG & Exp. SVG & 1 & -- & 1 & -- & 1 & -- \\
\hline \multirow{6}{*}{ Emotion } & F1 & 0.754 & -- & 0.710 & -- & 0.770 & - \\
\hline & $\mathrm{F} 2$ & 0.832 & 15.946 & 0.829 & 10.585 & 0.830 & 11.282 \\
\hline & F3 & 0.889 & 16.600 & 0.889 & 10.952 & 0.894 & 11.803 \\
\hline & $C R$ & 0.865 & & 0.852 & & 0.868 & \\
\hline & $A V E$ & 0.681 & & 0.660 & & 0.688 & \\
\hline & $\begin{array}{l}\text { Mean } \\
(S D)\end{array}$ & $\begin{array}{c}4.445 \\
(1.541) \\
\end{array}$ & & $\begin{array}{c}4.759 \\
(1.444) \\
\end{array}$ & & $\begin{array}{c}4.097 \\
(1.574) \\
\end{array}$ & \\
\hline \multirow[t]{3}{*}{ Cognition } & Cognitive Evaluation & 1 & -- & 1 & -- & 1 & -- \\
\hline & $M(S D)$ & $\begin{array}{c}4.563 \\
(1.791) \\
\end{array}$ & & $\begin{array}{c}5.157 \\
(1.767) \\
\end{array}$ & & $\begin{array}{c}3.904 \\
(1.579) \\
\end{array}$ & \\
\hline & Asvg1 & 0.821 & -- & 0.717 & -- & 0.725 & -- \\
\hline \multirow[t]{5}{*}{ SVG attitude } & Asvg2 & 0.891 & 20.760 & 0.867 & 11.210 & 0.783 & 9.262 \\
\hline & Asvg3 & 0.914 & 21.362 & 0.887 & 11.327 & 0.833 & 9.561 \\
\hline & $C R$ & 0.908 & & 0.864 & & 0.855 & \\
\hline & $A V E$ & 0.720 & & 0.652 & & 0.606 & \\
\hline & $\begin{array}{l}\text { Mean } \\
(S D)\end{array}$ & $\begin{array}{c}4.628 \\
(1.768) \\
\end{array}$ & & $\begin{array}{c}5.694 \\
(1.446) \\
\end{array}$ & & $\begin{array}{c}3.448 \\
(1.274) \\
\end{array}$ & \\
\hline \multirow{6}{*}{ Brand attitude } & $\mathrm{Ab} 1$ & 0.901 & -- & 0.872 & -- & 0.887 & -- \\
\hline & $\mathrm{Ab} 2$ & 0.914 & 27.379 & 0.896 & 17.538 & 0.898 & 16.737 \\
\hline & Ab3 & 0.918 & 27.574 & 0.932 & 18.664 & 0.888 & 16.460 \\
\hline & $C R$ & 0.935 & & 0.927 & & 0.924 & \\
\hline & $A V E$ & 0.827 & & 0.810 & & 0.803 & \\
\hline & $\begin{array}{l}\text { Mean } \\
(S D) \\
\end{array}$ & $\begin{array}{c}4.564 \\
(1.932) \\
\end{array}$ & & $\begin{array}{c}5.694 \\
(1.446) \\
\end{array}$ & & $\begin{array}{r}3.448 \\
(1.274) \\
\end{array}$ & \\
\hline
\end{tabular}

Notes. Critical Ratios was determined on unstandardized regression weights. Mean score of each construct were computed with summated score of items.

Attitude toward SVG and brand attitude. The attitudes toward SVG and sport brands were measured by a standard attitude semantic differential scale (Osgood, Suci, \& Tannenbaum, 1957) and has been used in other studies in which has established its validity and reliability (Campbell \& Keller, 2003; Muehling \& Laczniak, 1988). Subjects were asked to rate their overall feelings about the SVG and the brands respectively on a 3-item, 7-point semantic differential scale, bounded by "favorable-unfavorable", "dislike-like", and "positive-negative".

Brand familiarity. The familiarity of the sport brand was assessed using a 3-item, 7-point semantic differential scale, bounded by "unfamiliar-familiar", "inexperienced-experienced", and "no-information-a great deal of information", which was originally developed by Kent and Allen (1994). Two respondent segments of roughly equal size were formed by splitting at the median: high and low. A homogeneity of variance test based 
on median was conducted to ensure whether two segments are statistically comparable on levels of brand familiarity. Levene's test indicated equal variances in the segments $(F=2.870, p=0.058)$.

\section{Data Analysis}

Following Kline's (2005) suggestions, the current study implemented a three-stage procedure: (1) model assessment; (2) model re-specification; and then (3) invariance-testing for multi-group path analysis. The proposed conceptual model with brand familiarity defined as a moderator was estimated with a maximum likelihood estimation procedure by using Analysis of Moment Structure (AMOS) 18. The following sections provide a detail discussion of the analysis procedure.

Model assessment. A two-step approach was adopted to test the hypothesized relationships in the research model and measurement scale (Anderson \& Gerbing, 1988). First, a measurement model was tested to denote the conceptual distinctions among latent variables and to establish construct validity. Second, a structural model was tested to examine the overall model including the relationships among constructs.

Model respecification. The model was re-specified by deleting paths which were not statistically significant in both groups. Anderson and Gerbing's (1988) two-step approach and aforementioned model fit indices were adopted again to test the efficacy of the structural model and measurement model in an independent sample.

Testing for invariant pattern of the proposed model across groups. The configural, metric, and scalar invariance tests of the model were conducted to examine whether the factor structure of the model was consistent across levels of sport brand familiarity (low vs. high). After confirming the prerequisites for a multi-group path analysis, group differences in the path coefficients of latent variables were estimated by testing structural invariance with the specification of cross-group equality constraints (Ho, 2006).

\section{Results}

\section{Demographic Profile of Participants}

A total of 375 undergraduate students participated in the study. All subjects were between 18 and 27 years of age $(M=22.1 ; S D=4.4)$. The majority of the respondents $(60.5 \%)$ were White/Caucasian, $17.1 \%$ of the respondents were Asian/Pacific Islander, and $14.7 \%$ were Hispanic. The gender distribution of respondents was $21.1 \%$ female and $78.9 \%$ male, with $96.3 \%$ of the respondents indicating that they were single.

\section{Model Assessment}

Measurement model. Confirmatory factor analysis (CFA) was used to test the measurement properties of the model (Joreskog \& Sorbom, 1996). The results of the CFA indicated that the measurement model had an acceptable fit of the data. The chi-square/df ratio $\left(\chi^{2} / d f=150.08 / 36=4.17\right)$ was lower than the suggested threshold (i.e., less than 5.0; Wheaton, Muthen, Alwin, \& Summers, 1977). Other fit indices were thus closely considered: Comparative Fit Index $(\mathrm{CFI})=0.959$, Incremental Fit Index $(\mathrm{IFI})=0.960$, Tucker Lewis Index $(\mathrm{TLI})=0.938$, and Standardized Root Mean Square Residual $($ SRMR $)=0.037$ (Kelloway, 1998; Kline, 2010) Based on the overall results of the CFA, it is deemed that the measurement model is acceptable with good model fit and there is strong evidence of reliability and validity in the measurement scale.

Structural model. The results of the SEM analysis indicated a good fit of the research model to the data: $\chi^{2} / d f=160.16 / 38=4.21 ; \mathrm{CFI}=0.957 ; \mathrm{IFI}=0.957 ; \mathrm{TLI}=0.937 ; \mathrm{SRMR}=0.047$. Furthermore, all hypothesized paths were significant and in expected directions except for a linkage between cognition and brand attitudes. 
Table 2

Average Variance Extracted (AVE) and Squared Correlations (Convergent/Discriminant Validity)

\begin{tabular}{llcccc}
\hline & $\begin{array}{l}\text { Exposure to } \\
\text { SVG }\end{array}$ & Emotion & Cognition & SVG attitude & Brand attitude \\
\hline High Brand Familiarity Group $(n=197)$ & & & & & \\
Exposure to SVG & - & & & & \\
Emotion & 0.108 & $(0.660)$ & & & \\
Cognition & 0.127 & 0.328 & -- & & \\
SVG attitude & 0.027 & 0.120 & 0.154 & $(0.652)$ & \\
Brand attitude & 0.024 & 0.088 & 0.165 & 0.365 & $(0.810)$ \\
\hline Low Brand Familiarity Group $(n=178)$ & & & & & \\
Exposure to SVG & -- & & & & \\
Emotion & 0.050 & $(0.688)$ & & & \\
Cognition & 0.073 & 0.238 & -- & & \\
SVG attitude & 0.008 & 0.028 & 0.112 & $(0.606)$ & \\
Brand attitude & 0.006 & 0.019 & 0.076 & 0.366 & $(0.803)$ \\
\hline
\end{tabular}

Notes. Diagonal values are the AVE; Off-diagonal values are the squared correlations between variables.

Table 3

Estimated Structural Relations Coefficients

\begin{tabular}{|c|c|c|c|c|}
\hline Hypothesized relationships & $\begin{array}{l}\text { Unstandardized coeffficient } \\
\text { (Standardized coefficient) }\end{array}$ & S.E. & Critical ratios & p-value \\
\hline \multicolumn{5}{|l|}{ High brand familiarity group } \\
\hline H1 Exposure to SVG $\rightarrow$ Emotion & $0.225(0.356)$ & 0.048 & 4.658 & 0.000 \\
\hline H2 Exposure to SVG $\rightarrow$ Cognition & $0.350(0.329)$ & 0.072 & 4.875 & 0.000 \\
\hline H3 Emotion $\rightarrow$ Brand attitude & $0.303(0.199)$ & 0.112 & 2.709 & 0.007 \\
\hline H4 Cognition $\rightarrow$ Brand attitude & -- & -- & -- & -- \\
\hline H5 Emotion $\rightarrow$ SVG attitude & $0.339(0.289)$ & 0.115 & 2.936 & 0.003 \\
\hline H6 Cognition $\rightarrow$ SVG attitude & $0.127(0.182)$ & 0.062 & 2.037 & 0.042 \\
\hline H7 SVG attitude $\rightarrow$ Brand attitude & $0.685(0.526)$ & 0.108 & 6.352 & 0.000 \\
\hline Indirect effects & & & $p$-value & \\
\hline Exposure to SVG $\rightarrow$ SVG attitude & $0.121(0.163)$ & 0.045 & 0.014 & \\
\hline Exposure to SVG $\rightarrow$ Brand attitude & $0.151(0.156)$ & 0.044 & 0.007 & \\
\hline Emotion $\rightarrow$ Brand attitude & $0.232(0.152)$ & 0.072 & 0.008 & \\
\hline Cognition $\rightarrow$ Brand attitude & $0.087(0.096)$ & 0.060 & 0.116 & \\
\hline \multicolumn{5}{|l|}{ Low Brand Familiarity Group } \\
\hline H1 Exposure to SVG $\rightarrow$ Emotion & $0.234(0.271)$ & 0.068 & 3.425 & 0.000 \\
\hline H2 Exposure to SVG $\rightarrow$ Cognition & $0.217(0.224)$ & 0.071 & 3.061 & 0.002 \\
\hline H3 Emotion $\rightarrow$ Brand attitude & $0.094(0.081)$ & 0.089 & 1.059 & 0.290 \\
\hline H4 Cognition $\rightarrow$ Brand attitude & -- & -- & -- & -- \\
\hline H5 Emotion $\rightarrow$ SVG attitude & $0.282(0.331)$ & 0.088 & 3.219 & 0.001 \\
\hline H6 Cognition $\rightarrow$ SVG attitude & $0.005(0.006)$ & 0.070 & 0.068 & 0.946 \\
\hline H7 SVG attitude $\rightarrow$ Brand attitude & $0.792(0.580)$ & 0.126 & 6.306 & 0.000 \\
\hline Indirect effects & & & p-value & \\
\hline Exposure to SVG $\rightarrow$ SVG attitude & $0.067(0.091)$ & 0.041 & 0.030 & \\
\hline Exposure to SVG $\rightarrow$ Brand attitude & $0.075(0.075)$ & 0.043 & 0.014 & \\
\hline Emotion $\rightarrow$ Brand attitude & $0.223(0.192)$ & 0.065 & 0.013 & \\
\hline Cognition $\rightarrow$ Brand attitude & $0.004(0.004)$ & 0.053 & 0.997 & \\
\hline
\end{tabular}

Note. Standard errors and $p$-values of all indirect effects were estimated with bootstrap analysis. 


\section{Model Respecification and Test of Hypotheses}

The results of path analysis showed that the path between cognition and brand attitudes was not statistically significant $(\beta=-0.040, p=0.602$ for high brand familiarity group; and $\beta=0.044, p=0.573$ for low brand familiarity group). Accordingly, the model was re-specified by deleting the path to ensure parsimony of the model (Anderson \& Gerbing, 1988). SEM analyses were then conducted to test the fit of the respecified model that included the hypothesized relations among the constructs as shown in Figure 1. This model provided a good fit to the data according to all criteria: $\chi^{2} / d f=160.25 / 39=4.11 ; \mathrm{CFI}=0.957$; IFI $=0.957$; TLI $=0.939$; $\mathrm{SRMR}=0.048$. The chi-square difference $\left(\right.$ diff $\left.^{2}=0.089\right)$ and degrees of freedom $($ diff $d f=1)$ values indicated that the re-specified model and the original model did not differ significantly in their goodness-of-fit. Furthermore, all hypothesized paths for the high brand familiarity group were significant and in expected directions (see Table 3 and Figure 2). Table 3 summarized the hypotheses testing results.

\section{Testing for Invariant Pattern of Structure Model Across the Levels of Brand Familiarity}

Prior to conducting multi-group invariance testing, the configural, metric, and scalar invariance tests of the model were performed (see Table 4). A multi-group path analysis was next conducted to test group differences in path coefficients within the proposed model by constraining all path coefficients (factor loadings and structural weights) to be the same across two groups (the group-invariant model). The group invariant model was compared to the group variant model in which the factor coefficients were constrained to be equal. The results, as shown in Table 4, indicated that the difference in $\chi^{2}$ values of the two models was not statistically significant: $\Delta \chi^{2}(6)=7.007, p>0.05$. The models thus do not differ significantly in terms of their goodness of fit.

To test the statistical significance of the difference between the path coefficients for the two groups, pairwise parameter comparisons were performed. Critical ratios for difference between the parameters revealed no significant differences in all paths. This confirmed that the hypothesized relationships between research variables similarly operated across levels of brand familiarity.

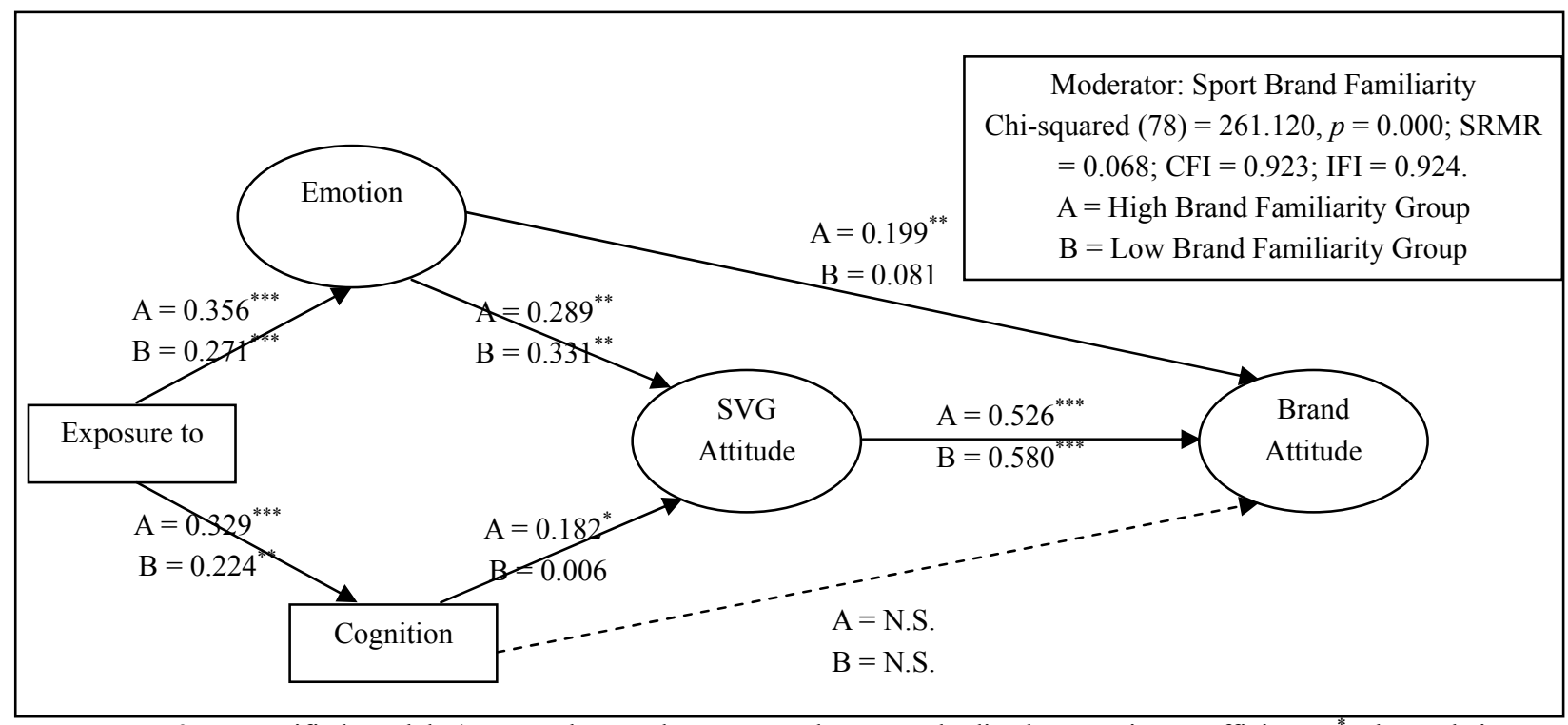

Figure 2. Respecified model. (Notes. The numbers reported are standardized regression coefficients; ": the path is significant at 0.05 level; ${ }^{* *}$ : the path is significant at 0.01 level; ${ }^{* * *}$ : the path is significant at 0.001 level). 
Table 4

Fit Indices and Results for Invariance Tests Across Levels of Brand Familiarity

\begin{tabular}{|c|c|c|c|c|c|c|c|c|c|c|}
\hline No. & Model & $X^{2}$ & $d f$ & SRMR & CFI & IFI & $\begin{array}{l}\text { Nested models } \\
\text { comparison }\end{array}$ & $\Delta \chi^{2}$ & $\Delta d f$ & $p$ \\
\hline 1 & $\begin{array}{l}\text { Configural invariance } \\
\text { (Baseline model) }\end{array}$ & 261.120 & 78 & 0.068 & 0.923 & 0.924 & & & & \\
\hline 2 & Full metric invariance & 264.586 & 82 & 0.067 & 0.923 & 0.924 & $2-1$ & 3.466 & 4 & $p>0.05$ \\
\hline 3 & Full scalar invariance & 294.641 & 90 & 0.068 & 0.914 & 0.914 & $3-2$ & 30.055 & 8 & $p=0.001$ \\
\hline 4 & Factor loadings invariance & 264.586 & 82 & 0.067 & 0.923 & 0.924 & & & & \\
\hline 5 & $\begin{array}{l}\text { Factor loadings and structural } \\
\text { weight invariance }\end{array}$ & 271.593 & 88 & 0.080 & 0.923 & 0.923 & $5-4$ & 7.007 & 6 & $p>0.05$ \\
\hline
\end{tabular}

Notes. $\chi^{2}=$ Likelihood-ratio chi-square, $d f=$ Degree of Freedom, SRMR $=$ Standardized Root Mean Square Residual, CFI $=$ Comparative Fit Index, IFI = Incremental Fit Index.

\section{Discussion}

The purpose of this study were to develop and test a conceptual model delineating the relationship between repeated SVG play and consumers' responses to a sport brand embedded in a SVG; and examine if the model has the same pattern across levels of brand familiarity. The results supported all research hypotheses except a path linking brand cognition to brand attitudes (H4). The empirical evidence from the study shows that repeated exposures to a sport brand in SVG lead to positive emotional reactions and cognitive evaluation about the sport brand. The effects of emotional and cognitive reactions to the sport brand on SVG attitudes and brand attitudes vary across levels of brand familiarity. Emotional reaction to a familiar brand in SVG has a direct influence on SVG attitudes and brand attitudes. On the contrary, emotional reactions to an unfamiliar brand are indirectly transferred to brand attitudes through SVG attitudes. Indirect effects of brand cognition on brand attitudes through SVG attitudes were evident in high levels of brand familiarity but not in low levels of brand familiarity. It is evident that brand familiarity moderates the relationship among constructs in the research model.

Regarding the effect of repeated SVG play on consumers' emotional and cognitive reactions, the results confirmed that the repetition of SVG elicits positive emotional reactions to a sport brand (H1) and cognitive evaluation about the sport brand (H2). This is consistent with previous research indicating that increased exposure to an object leads to positive feelings about a stimulus object (Gupta \& Lord, 1998; Zajonc, 1968). The findings also provide empirical evidence that SVG repetition allows users to have more opportunity to evaluate and elaborate on sport brands embedded in SVG, which in turn could lead to increased cognitive elaboration and the strengthened association between the brand and its evaluation.

In terms of the moderating effect of brand familiarity on attitude formation processing (H8), the findings demonstrated that emotional responses to a sport brand have a differential impact on attitudes toward the brand across levels of brand familiarity. The results of multiple-group path analysis indicated that emotional responses to a sport brand influence attitudes toward the sport brand (H3), for only those individuals with high levels of brand familiarity. In addition, the study demonstrated the effect of brand familiarity on the relationship between cognitive evaluation about a sport brand and SVG attitudes (H6). The findings indicated that only the path coefficient in individuals with high levels of brand familiarity was found to be significant. The empirical evidence confirms the moderating effect of brand familiarity on the relationship between emotional reaction and brand attitudes (H3) and on the relationship between cognitive evaluation and SVG attitudes (H6). The 
findings also provide insight into how sport experience in real-life influences sport brand attitude formation in SVG contexts.

For both high and low brand familiarity groups, a significant relationship between emotional reactions and attitudes toward SVG (H5) was identified. The finding is consistent with research suggesting that media-induced affect can be transferred to media attitudes (Erdley \& D'Agostino, 1988). In addition, this study showed indirect effects of emotional reactions to a sport brand on brand attitudes through SVG attitudes confirming the relationship between SVG attitudes and brand attitudes (H6). Considering that emotional reactions to an unfamiliar sport brand have no direct influences on sport brand attitudes ( $\mathrm{H} 3$ and $\mathrm{H} 8$ ), the finding indicates that SVG users' emotional reactions are indirectly transferred to brand attitudes through SVG attitudes. This provides insight into the potential of SVG as a marketing communication tool for reaching non-sport fans.

Regarding the relationship between cognition and brand attitudes, H4 was eliminated in the model respecification. Contrary to the finding of Fishbein's (1963) study, a significant relationship between cognition and sport brand attitudes did not emerge in the current study. Such a finding is however not entirely expected in this study, which implies that cognitive activities involved in playing SVG differ from the passive nature of watching advertising on other media (e.g., newspaper, radio, television). According to Nicovich (2005), individuals focus on playing games rather than processing information about brands in the games because of the interactive nature of games. It could be suggested that cognitive information processing is more likely to occur when processing the sport brand within SVG is the primary focus of attention. The results are encouraging for the continued understanding of the effects of other factors (e.g., required skills for playing SVG) on the relationship between cognition and brand attitude in SVG contexts.

\section{Implications}

The current study extends the line of research on SVG effectiveness focusing on repeated SVG play and brand familiarity as a relevant construct. One contribution of this study to the body of knowledge lies in developing a theoretical understanding of emotional and cognitive reactions elicited by repeated exposure to a sport brand in SVG-based attitude formation. Although initially repetition effects were examined on cognitive reactions (e.g., Cacioppo \& Petty, 1979), this study enriches the related literature by incorporating the relatively important emotional reaction as well as cognitive reaction in the model.

In addition, this study makes contributions to the existing literature on the effects of brand familiarity on the relationship between message repetition and its effects. The findings provide empirical evidence that emotional and cognitive reactions to a familiar or unfamiliar brand differ with repetition in the SVG environment. This would benefit sport researchers who are eager to unravel the potential of SVG as a marketing tool for reaching existing and new market segments.

The findings of this study provide sport marketers with sufficient evidence to validate the use of SVG as a marketing communication tool. Sport practitioners would encourage sport consumers including sport fans and non-sport fans to get involved in SVG playing. This could be achieved, for example, through a SVG competition for promoting sporting events. For SVG users who are non-sport fans, it might be helpful to advertise and educate both a sport brand and its SVG simultaneously. For instance, the Major League Soccer (MLS) may utilize and promote advertising themes with the contents of its star players and MLS video games by focusing on entertainment and fun aspects of the real life MLS games. 
In addition, the findings of this study provide sport marketers and game developers with meaningful implications for practice. The study shows empirical evidence that individuals form their attitudes toward unfamiliar sport brands through SVG play. In other words, individuals who have positive gaming experiences are more likely to produce positive responses to the SVG, which leads to attitudes toward the brand. According to Kwak et al. (2010), SVG users who utilized the personalization option spend more time playing SVG than those who do not. Based on previous findings, the logical extension would be that using personalization options results in a positive gaming experience, and this leads to favorable attitudes toward SVG. Thus, sport marketers should be actively involved in the development of SVG, which enhance users' gaming experience.

\section{Limitations and Future study}

There are several limitations in this study that need to be addressed. First, this study utilized only a soccer-themed-video game and a sport league brand to test the hypotheses. In this study, the potential impact of other sport brands such as teams and players in SVG was not examined in this study. Therefore, future researchers should consider replicating this study with a focus on other sport brands in the different types of SVG.

Another limitation of this study is related to the effects of other constructs (e.g., prior experience with video games, gaming skills, involvement, etc.) on attitudinal response to the sport brand in SVG. Previous research on brand placement in video games has identified users' gaming skill as a potential confound in desired advertising outcomes (e.g., Kuhn \& Pope, 2010). Therefore, future research should address and control the effect of users' gaming skills developed from prior experience with video games.

Lastly, the student sample used in this study has limitations. The data reported here may reflect virtual sport experiences among the relatively young and highly educated game players. While these segments well represent the most valuable video game consumers (Weaver, 2013), the sample may not necessarily be representative of the SVG user population. Therefore, a random sample from the population should be included in future research to increase generalizability of findings of the present research.

\section{References}

Aaker, D., \& Stayman, D. (1990). Measuring audience perceptions of commercials and relating them to ad impact. Journal of Advertising Research, 30, 7-17.

Anderson, J., \& Gerbing, D. (1988). Structural equation modeling in practice: A review and recommended two-step approach. Psychological Bulletin, 103, 411-423.

Belch, G. (1982). The effects of television commercial repetition on cognitive response and message acceptance. Journal of Consumer Research, 9, 56-66.

Biscaia, R., Correia, A., Rosado, A., Maroco, J., \& Ross, S. (2012). The effects of emotions on football spectators' satisfaction and behavioral intentions. European Sport Management Quarterly, 21, 227-242.

Biswas, A., \& Sherrell, D. (1993). The influence of product knowledge and brand name on internal price standards and confidence. Psychology \& Marketing, 10, $31-46$.

Broverman, A. (2010, June 13). Top 10: Best-selling video game franchises. Retrieved from http://www.askmen.com/top_10/entertainment_300/317b_top_10_list.html

Cacioppo, J., \& Petty, R. (1981). Social psychological procedures for cognitive response assessment: The thought-listing technique. In C. R. Glass, T. V. Merluzzi, \& M. Genest (Eds.), Cognitive assessment (pp. 309-342). NY: Guilford Press.

Cacioppo, J., \& Petty, R. (1979). Effects of message repetition and position on cognitive responses, recall, and persuasion. Journal of Personality and Social Psychology, 37(1), 97-109.

Calder, B., Phillips, L., \& Tybout, A. (1981). Designing research for application. Journal of Consumer Research, 8, 197-207. 
Calder, B., \& Sternthal, B. (1980). Television commercial wearout: An information processing view. Journal of Marketing Research, 17, 173-186.

Campbell, M., \& Keller, K. (2003). Brand familiarity and advertising repetition effects. Journal of Consumer Research, 30 , 292-304.

Cianfrone, B., Zhang, J., Trail, G., \& Lutz, R. (2008). Effectiveness of in-game advertisements in sport video games: An experimental inquiry on current gamers. International Journal of Sport Communication, 1, 195-218.

Edell, J., \& Burke, C. (1987). The power of feelings in understanding advertising effects. Journal of Consumer Research, 14, 421-433.

Entertainment Software Association. (2012). Essential facts about the computer and video game industry. Washington, D.C.: Author. Retrieved from www.theesa.com/facts/pdfs/esa_ef_2012.pdf

Erdley, C., \& D'Agostino, P. (1988). Cognitive and affective components of automatic priming effects. Journal of Personality and Social Psychology, 54, 741-747.

Fishbein, M. (1963). An investigation of the relationships between beliefs about an object and the attitude toward that object. Human Relations, 16, 233-240.

Fishbein, M., \& Ajzen, I. (1972). Attitudes and opinions. Annual Review of Psychology, 23, 487-544.

Gupta, P., \& Lord, K. (1998). Product placement in movies: The effect of prominence and mode on audience recall. Journal of Current Issues and Research in Advertising, 20(1), 47-59.

Harley, R., \& Baldinger, A. (1991). The ARF copy research validity project. Journal of Advertising Research, 31, 11-32.

Ho, R. (2006). Handbook of univariate and multivariate data analysis and interpretation with SPSS. Danvers, M.A.: Chapman \& Hall/CPC.

Joreskog, K., \& Sorbom, D. (1996) LISREL 8: User's reference guide. Chicago: Scientific Software International.

Katz, D., \& Stotland, E. (1959). A preliminary statement to a theory of attitude structure and change. In S. Koch (Ed.), Psychology: A study of a science, 3. New York: McGraw-Hill, 423-475.

Kelloway, K. (1998). Using LISREL for structural equations modeling: A researcher's guide. Thousand Oaks, C.A.: Sage Publications.

Kent, R., \& Allen, C. (1994). Competitive interference effects in consumer memory for advertising: The role of brand familiarity. Journal of Marketing, 58, 97-105.

Kim, Y. (2010). The effects of virtual sport experiences on attitude and attitude strength (Doctoral dissertation, University of Minnesota, 2010). Retrieved from conservancy.umn.edu.

Kim, Y., \& Ross, S. (2006). An exploration of motives in sport video gaming. International Journal of Sports Marketing \& Sponsorship, 8, 34-46.

Kim, Y., Walsh, P., \& Ross, S. (2008). The examination of psychological and consumptive behavior of sport video gamers. Sport Marketing Quarterly, 17(1), 44-53.

Kline, R. (2010). Principles and practice of structural equation modeling (3rd ed.). New York: The Guilford Press.

Kuhn, K. A., \& Pope, N. (2010). The effect of video game placements on brand attitude. In: Proceedings of American Marketing Association Summer Marketing Educators' Conference, 13- 16 August, 2010, Boston Marriott Copley, Boston.

Kwak, D., Clavio, G., Eagleman, A., \& Kim, K. (2010). Exploring the antecedents and consequences of personalizing sport video game experiences. Sport Marketing Quarterly, 19, 217-225.

MacKenzie, S., \& Lutz, R. (1989). An empirical examination of attitude toward the ad as a mediator of advertising effectiveness. Journal of Marketing, 53, 48-65.

MacKenzie, S., Lutz, R., \& Belch, G. (1986). The role of attitude toward the Ad as a mediator of advertising effectiveness: A test of competing explanations. Journal of Marketing Research, 23, 130-143.

"Madden" Simulation. (2013). Super Bowl 2013: Madden '13 simulation predicts Ravens win. Retrieved from http://espn.go.com/blog/playbook/tech/post/_id/3933/madden-nfl-13-simulates-the-super-bowl

Muehling, D. (1987). An investigation of factors underlying attitude-toward-advertising-in-general. Journal of Advertising Research, 16(1), 32-40.

Muehling, D., \& Laczniak, R. (1988). Advertising's immediate and delayed influence on brand attitudes: Considerations across message involvement levels. Journal of Advertising, 17, 23-34.

Nelson, M. (2002). Recall of brand placements in computer/video games. Journal of Advertising Research, 42, 80-92.

Nelson, M., Keum, H., \& Yaros, R. (2004). Advertainment or adcreep? Game players' attitudes toward advertising and product placements in computer games. Journal of Interactive Advertising, 5(1), 3-30. 
Nicovich, S. (2005). The effect of involvement on ad judgment in a video game environment: The mediating role of presence. Journal of Interactive Advertising, 6(1), 38-51.

Osgood, C., Suci, G., \& Tannenbaum, P. (1957). The measurement of meaning. Urbana, I.L.: University of Illinois Press.

Rosenberg, E. (1968). Levels of analysis and organization of affect. Review of General Psychology, 2, 247-270.

Rosenberg, M., \& Hovland, C. (1960). Cognitive, affective, and behavioral components of attitudes. In C. I. Hovland, \& M. J. Rosenberg (Eds.), Attitude organization and change: An analysis of consistency among attitude components (pp. 1-14). New Haven, C.T.: Yale University Press.

Ross, S., James, J., \& Vargas, P. (2006). Development of a scale to measure team brand associations in professional sport. Journal of Sport Management, 20, 260-279.

Vakratsas, D., \& Ambler, T. (1999). How advertising works: What do we really know. Journal of Marketing, 63, 26-43.

Walsh, P., Kim, Y., \& Ross, S. (2008). Brand recall and recognition: A comparison of television and video games as presentation modes. Sport Marketing Quarterly, 17, 201-208.

Weaver, J. (2013). College students are avid gamers. Retrieved from http://www.nbcnews.com/id/3078424/

Wheaton, B., Muthen, B., Alwin, D., \& Summers, G. (1977). Assessing reliability and stability in panel models. Sociological Methodology, 8, 84-136.

Zajonc, R. (1968). Attitudinal effects of mere exposure. Journal of Personality and Social Psychology. Monograph Supplement, 9 , $1-27$. 